\title{
Peak Inspiratory Flow Rate in COPD: An Analysis of Clinical Trial and Real-World Data
}

This article was published in the following Dove Press journal:

International Journal of Chronic Obstructive Pulmonary Disease

\author{
Martin Anderson (ID) \\ Kathryn Collison ${ }^{2}$ \\ M Bradley Drummond $\mathbb{1}^{3}$ \\ Melanie Hamilton ${ }^{4}$ \\ Renu Jain $\mathbb{D}^{2}$ \\ Neil Martin ${ }^{5,6}$ \\ Richard A Mularski $\mathbb{1 D}^{7}$ \\ Mike Thomas ${ }^{8}$ \\ Chang-Qing Zhu (D) ${ }^{9}$ \\ Gary T Ferguson ${ }^{10}$
}

\begin{abstract}
'Department of Laboratory Medicine, Karolinska Institutet, Stockholm, Sweden;

${ }^{2}$ Respiratory Therapy Area, GSK,

Research Triangle Park, NC, USA;

${ }^{3}$ Pulmonary and Critical Care Medicine, University of North Carolina at Chapel Hill, Chapel Hill, NC, USA; ${ }^{4}$ R\&D, GSK,

Ware, Hertfordshire, UK; ${ }^{5}$ Global Medical Affairs, GSK, Brentford, Middlesex, UK; ${ }^{6}$ Institute for Lung Health, University of Leicester, Leicester, Leicestershire, UK; ${ }^{7}$ Department of Pulmonary and Critical Care Medicine, Kaiser Permanente Northwest Center for Health Research, Portland, OR, USA; ${ }^{8}$ Primary Care Research, University of Southampton, Southampton, UK; 'Biostatistics, GSK, Stockley Park West, Uxbridge, Middlesex, UK; ${ }^{10}$ Pulmonary Research, Institute of Southeast Michigan, Farmington Hills, MI, USA
\end{abstract}

Background: The influence of peak inspiratory flow (PIF) on dose delivery from dry powder inhalers (DPIs) and association with treatment efficacy in patients with chronic obstructive pulmonary disease (COPD) has not been fully determined. In vitro studies have demonstrated adequate dose delivery through ELLIPTA DPI at PIF $\geq 30 \mathrm{~L} / \mathrm{min}$. This analysis of two clinical trials and a real-world population of COPD patients determined spirometric PIF distribution, and explored the relationship between PIF and outcomes in the trials.

Methods: The replicate Phase IV, 12-week, randomized, double-blind 207608/207609 (NCT03478683/NCT03478696) trials evaluated fluticasone furoate/umeclidinium/vilanterol via ELLIPTA DPI versus budesonide/formoterol+tiotropium in COPD patients. This post hoc analysis assessed spirometric PIF distribution at screening and relationship between PIF and lung function outcomes in the pooled 207608/207609 population. Spirometric PIF distributions in a real-world population of COPD patients were evaluated by retrospective analysis of the Kaiser Permanente Northwest (KPNW) database to assess similarities between clinical trial and real-world populations.

Results: A total of 1460 (207608/207609) and 3282 (KPNW) patients were included. There was considerable overlap between spirometric PIF distributions for both populations. Overall, $99.7 \%$ and $99.8 \%$ of the $207608 / 207609$ and KPNW populations, respectively, reported spirometric PIF $\geq 50 \mathrm{~L} / \mathrm{min}$, estimated as equivalent to ELLIPTA PIFR $\geq 30 \mathrm{~L} / \mathrm{min}$. In the 207608/207609 combined analysis, there was no significant interaction between spirometric PIF and treatment for lung function endpoints, indicating treatment effect is independent of PIF.

Conclusion: Nearly all COPD patients in the 207608/207609 and KPNW populations achieved spirometric PIF values estimated as equivalent to PIFR of $\geq 30 \mathrm{~L} / \mathrm{min}$ through the ELLIPTA DPI. Lack of correlation between spirometric PIF at screening and treatment efficacy aligns with consistent dose performance from the ELLIPTA DPI across a wide range of PIFs, achieved by patients with COPD of all severities.

Keywords: COPD, inhaled triple therapy, patient outcomes, real-world studies, peak inspiratory flow rate, DPI

\section{Introduction}

Dry powder inhalers (DPIs) have become one of the main administration devices for chronic obstructive pulmonary disease (COPD) therapies. Studies have shown that patients generally prefer using DPIs compared with traditionally used metered dose inhalers (MDIs). ${ }^{1}$ The ELLIPTA DPI device, compared with MDIs, has been associated with shorter training times, fewer errors in use, less requirement for coordination, environmental benefits and greater patient preference, with
Correspondence: Gary T Ferguson

Pulmonary Research, Institute of

Southeast Michigan, Farmington Hills, MI, USA

$\mathrm{Tel}+\mid$ 248-478-656।

Email garytferguson@msn.com
International Journal of Chronic Obstructive Pulmonary Disease 2021:16 933-943

933

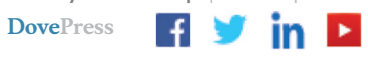

http://doi.org/| 0.2147/COPD.S29|554 
implications for adherence and potentially treatment outcomes. $^{2,3}$ The ELLIPTA DPI has also been shown to be easy to use with few errors in use across different age groups in patients with COPD. ${ }^{4}$ In order to use DPIs adequately, patients must generate a level of inspiratory effort based on the internal resistance of the inhaler, and thereby provide energy for dose emission and deaggregation of the inhalation powder to generate particles of a suitable size for deposition within the lower respiratory tract. ${ }^{5-7}$

The peak inspiratory flow (PIF) is the maximal flow achieved by an individual during an inspiratory manoeuvre and is measured during clinical practice using spirometry or by devices designed to mimic inhaler-specific resistance. $^{8,9}$ There is no consistent evidence of an association between inhaler-specific PIF and expiratory measures, such as forced expiratory volume in 1 second $\left(\mathrm{FEV}_{1}\right)$, nor with $\mathrm{FEV}_{1} \%$ predicted. ${ }^{8,10}$ Dynamic compression of the airway in COPD impairs exhalation resulting in reduced $\mathrm{FEV}_{1}$ and peak expiratory flow, but has no effect on PIFRs which are dependent on the inspiratory pressure generated by muscles used during respiration. ${ }^{10,11}$ The data from several previous studies have demonstrated inconsistent correlation between spirometric PIF and inhaler-specific PIF., ${ }^{8,-14}$

Although threshold spirometry and inhaler-specific PIF values are yet to be fully determined, a PIF value of $\geq 60 \mathrm{~L} / \mathrm{min}$ is often described as "optimal" for most DPIs to ensure medication de-aggregation and lower respiratory tract disposition. ${ }^{6,8,9,15}$ However, based on the findings of in vitro and small-scale observational studies, minimum and optimal inhaler-specific PIF values ranging from 20 to $50 \mathrm{~L} / \mathrm{min}$ and from 30 to $65 \mathrm{~L}$ / min, respectively, have also been reported for different DPIs. ${ }^{9,16,17}$ The majority (87-100\%) of patients with stable COPD or who have experienced an acute COPD exacerbation can achieve an inhaler-specific PIF $\geq 30 \mathrm{~L} / \mathrm{min}^{18-20}$ Additionally, a previous clinical trial demonstrated that the lowest PIF value obtained through the moderate resistance of the ELLIPTA DPI (two-strip configuration) was $43.5 \mathrm{~L} / \mathrm{min}$ in a patient with very severe COPD, and the highest value of $123.6 \mathrm{~L} / \mathrm{min}$ in a patient with mild COPD. ${ }^{14}$ Subsequent use of these profiles using the Electronic Lung, a breathing simulator designed for characterizing inhalation devices through replication of patient-specific inhalation profiles, demonstrated consistent dose delivery (ranging from $82.7 \%$ to $95.5 \%$ of nominal blister content) of each component of fluticasone furoate/umeclidinium/vilanterol (FF/ UMEC/VI) triple therapy with little dependence on $\mathrm{PIF}^{21}$ Furthermore, each component of FF/UMEC/VI has also been shown to be delivered consistently in vitro through the ELLIPTA inhaler at flow rates ranging from 30, 60 and $90 \mathrm{~L} / \mathrm{min}$ (standard impactor conditions). ${ }^{22,23}$ Together, this suggests that nearly all patients should receive sufficient dose delivery through the ELLIPTA DPI. We report here novel analyses of data from large scale randomized controlled trials (RCTs) and real-world clinical practice confirming these results.

The 207608 (NCT03478683) and 207609 (NCT03478696) studies demonstrated that FF/UMEC/VI triple therapy was non-inferior to budesonide/formoterol plus tiotropium at improving lung function and health status, with a similar safety profile, in patients with COPD. ${ }^{24}$ These studies provide a useful clinical trial population in which to examine the relationship between spirometric PIF and treatment outcomes. As results from RCTs may not always reflect clinical practice, ${ }^{25}$ the comparison with patients from a real-world population database will be informative to assess the applicability of the clinical trial outcomes to real-world clinical practice settings, as reported here.

The objective of this post hoc analysis of studies $207608 / 207609$ and a real-world population of patients with COPD was to determine the distribution of spirometric PIFs and the similarity between the RCT and realworld populations. A further objective was to assess any potential relationship between spirometric PIF and lung function response to treatment in patients with COPD in the RCTs.

\section{Materials and Methods Clinical Studies 207608 and 207609}

The clinical studies 207608 (NCT03478683) and 207609 (NCT03478696) were replicate Phase IV, 12-week, randomized, double-blind, parallel-group, multicenter, non-inferiority trials evaluating once-daily FF/UMEC/VI 100/62.5/25 $\mu \mathrm{g}$ (delivered dose: $92 / 55 / 22 \mu \mathrm{g}$ ) triple therapy delivered via the ELLIPTA DPI versus twice-daily budesonide/formoterol 200/6 $\mu$ g (total delivered dose: $320 / 9 \mu \mathrm{g}$ ) delivered via an MDI plus once-daily tiotropium $18 \mu \mathrm{g}$ (BUD/FOR+TIO) delivered via the HandiHaler in patients with COPD. ${ }^{24}$ The design of these studies, including the inclusion/exclusion criteria, have been described previously. ${ }^{24}$ In brief, eligible patients were outpatients $\geq 40$ years of age with an established history of COPD, a COPD Assessment Test (CAT) score of $\geq 10$ and a post-bronchodilator $\mathrm{FEV}_{1}<50 \%$ predicted, or $<80 \%$ predicted with $\geq 2$ moderate or $\geq 1$ severe exacerbation within the previous year. Patients needed to show compliance with the inhaler during the run-in period, but 
there were no protocol-defined exclusion criteria pertaining to screening PIF values or inhaler technique.

PIF was measured by routine spirometry at screening. All spirometry measurements were taken using standardized spirometry equipment (ERT) and electronic clinical assessments. Prior to spirometric PIF testing, patients were required to withhold their morning dose of COPD therapy, including rescue albuterol, for $\geq 4$ hours. Spirometric PIF was then assessed 10 minutes prior to pre-bronchodilator spirometry. Patients engaged with the mouthpiece of the spirometer with nose clip on and continued tidal breathing until relaxed. At least three and no more than eight complete maximal flow volume loops were obtained for each patient, with the highest PIFR measurement recorded being reported for each patient.

\section{Kaiser Permanente Northwest Database}

Kaiser Permanente Northwest (KPNW) is a group-model, managed care organization, which provides care to approximately 600,000 insured members in Northwest Oregon and Southwest Washington, USA. KPNW employs a fully electronic medical record, which is then used to populate administrative and clinical databases; these databases are available for use in approved research studies.

In the current retrospective, longitudinal analysis, patients in the KPNW database were included if they were $\geq 40$ years of age, classified as having COPD based on a COPD-related diagnosis code at $\geq 2$ outpatient visits within 12 months or $\geq 1$ inpatient visit between January 1, 2008 and December 31, 2017, and had recorded $\geq 1$ lung function test and PIF measurement, at a non-exacerbating time, between January 1, 2015 and December 31, 2017. Patients were also required to be enrolled in the health plan for $\geq 10$ months out of the year prior to inclusion.

All lung function testing was conducted in the outpatient setting. The most recent spirometric PIF for each patient was used in the analysis. As in the 207608/207609 studies, the spirometric PIF was recorded, derived from a normal spirometry procedure without superimposed flow resistance to simulate inhaler physics. As per the American Thoracic Society Guidelines, ${ }^{26}$ PIF was recorded as part of flow-volume manoeuvre with a maximal inhalation encouraged.

\section{Spirometric PIF Distribution and Association with Treatment Outcomes}

The distribution of measured spirometric PIF data was analyzed post hoc in the screening population from studies 207608/207609 and retrospectively in all patients included from the KPNW database, by graphical and descriptive analysis.

The estimated PIFR achieved through the moderateresistance ELLIPTA DPI was calculated from the measured spirometric PIF using an equation developed based on data from two previous studies in patients with COPD of all severities (RES113817/RES117178) (Supplementary Additional File 1). ${ }^{7}$ The proportions of patients with a spirometric PIF $\geq 50 \mathrm{~L} / \mathrm{min}$ were assessed in the pooled 207608/207609 population and the KPNW population. Spirometric PIF $\geq 50 \mathrm{~L} / \mathrm{min}$ was estimated to be equivalent to a lower $90 / 95 \%$ bound ELLIPTA PIF $\geq 30 \mathrm{~L} / \mathrm{min}$ (that is, a $95 \%$ confidence that $90 \%$ of the population has ELLIPTA PIF $\geq 30 \mathrm{~L} / \mathrm{min}$ ). This value was shown in vitro to be adequate for appropriate dose delivery. ${ }^{22,27}$ In the RES113817/RES117178 studies, ${ }^{14}$ from a total of 18 patients who had very severe COPD according to GOLD staging criteria, the minimum ELLIPTA PIF recorded from a patient was $43.5 \mathrm{~L} / \mathrm{min}$ (two-strip configuration). This same patient achieved a spirometric PIFR of $102.0 \mathrm{~L} / \mathrm{min}$, which based on the derived relationship between ELLIPTA and spirometric PIFR is estimated to be equivalent to an ELLIPTA PIFR of $\sim 37.7 \mathrm{~L} / \mathrm{min}$ (90/ 95\% lower bound) (Supplementary Additional File 1).

The association between spirometric PIF and the percentage predicted $\mathrm{FEV}_{1}$ at screening in the 207608/207609 pooled population was investigated. As patients randomized to treatment in the 207608/207609 studies demonstrated a similarly wide range of spirometric PIF values as patients who failed screening, patients with low spirometric PIF values were included in the intent-to-treat (ITT) population and analyses of treatment outcomes.

Post hoc testing of the interaction between spirometric PIF values at routine screening and treatment was conducted for four key lung function endpoints after 12 weeks of treatment in the pooled 207608/207609 ITT population. The key lung function outcomes assessed were the 0-24-hour weighted mean $\mathrm{FEV}_{1}$, trough $\mathrm{FEV}_{1}$, 12-hour $\mathrm{FEV}_{1}$ and the ratio of Week 12 to baseline trough $\mathrm{FEV}_{1}$. Interaction testing was conducted using a repeated measures model with covariates of study, baseline value, visit, geographical region, treatment, visit by treatment, visit by 
baseline interactions, PIF by treatment and PIF by treatment by visit interactions. Evidence of an interaction was assessed at the 5\% significance level.

\section{Results}

\section{Study Population and Baseline Demographics}

In total, 1951 patients had spirometric PIF measurements taken at screening in studies 207608/207609. The pooled 207608/609 ITT population comprised 1460 patients, 729 who received FF/ UMEC/VI and 731 who received BUD/FOR+TIO ${ }^{24} \mathrm{~A}$ total of 3282 patients in the KPNW database were included in the analysis.
Compared with the KPNW cohort, the pooled 207608/ 207609 clinical study population were younger (65.2 vs 68.4 years), with a lower body mass index (BMI) (28.5 vs $30.1 \mathrm{~kg} / \mathrm{m}^{2}$ ) and greater lung function impairment (as evidenced by greater proportions of patients with severe or very-severe airflow limitation [Global Initiative for Obstructive Lung Disease (GOLD) stage $3 / 4]^{28}$ ) (Table 1). Mean (standard deviation) screening spirometric PIF was 199.1 (78.6) vs 230.2 (89.7) L/min for patients in the pooled 207608/207609 and KPNW populations, respectively. There were also greater proportions of current smokers, patients with a history of $\geq 1$ moderate or severe exacerbations in the past year, and patients receiving triple or dual therapies for COPD in the clinical studies compared with the real-world population (Table 1). In the 207608/207609 clinical

Table I Baseline Patient Characteristics and Demographics

\begin{tabular}{|c|c|c|}
\hline & 207608/207609 (ITT Population; N= I 460) & KPNW (N=3282) \\
\hline Age, years, mean (SD) & $65.2(8.1)$ & $68.4(9.9)$ \\
\hline Female, n (\%) & $703(48.2)$ & $1533(46.7)$ \\
\hline BMI, kg/m², mean (SD) & $28.5(7.1)$ & $30.1(7.6)$ \\
\hline Current smoker, n (\%) & $714(48.9)$ & $1198(36.5)$ \\
\hline \multicolumn{3}{|l|}{$\begin{array}{l}\text { COPD exacerbations in the } \\
\text { previous } 12 \text { months, } n(\%)^{a}\end{array}$} \\
\hline 0 moderate/severe & $675(46.2)$ & $2458(74.9)$ \\
\hline$\geq 1$ moderate & $690(47.3)$ & $764(23.3)$ \\
\hline$\geq I$ severe & $175(12.0)$ & $60(1.8)$ \\
\hline Screening lung function & $n=1455$ & \\
\hline Post-BD FEV , (L), mean (SD) & $1.2(0.4)^{\mathrm{b}}$ & $1.9(0.7)$ \\
\hline & $n=1386$ & \\
\hline PIF (L/min), mean (SD) & 199.1 (78.6) & $230.2(89.7)$ \\
\hline \multicolumn{3}{|l|}{ GOLD grade, n (\%) } \\
\hline $\mathrm{I}\left(\mathrm{FEV}_{\mathrm{I}}>80 \%\right)$ & $0(0)$ & $516(16)$ \\
\hline $2(\mathrm{FEV}, 50-<80 \%)$ & $313(22)$ & $|43|(44)$ \\
\hline $3($ FEV, $30-<50 \%)$ & $902(62)$ & $514(16)$ \\
\hline $4\left(\mathrm{FEV}_{\mathrm{I}}<30 \%\right)$ & $240(16)$ & $74(2)$ \\
\hline \multicolumn{3}{|l|}{$\begin{array}{l}\text { COPD medications at } \\
\text { screening, } n(\%)^{c}\end{array}$} \\
\hline$I C S+L A M A+L A B A$ & $443(30)$ & $602(18)$ \\
\hline ICS + LABA & $496(34)$ & $409(13)$ \\
\hline LABA + LAMA & $223(15)$ & $8(<1)$ \\
\hline LAMA & $110(8)$ & II7I (36) \\
\hline
\end{tabular}

Notes: ${ }^{a}$ As some patients in 207608/207609 recorded both moderate and severe exacerbations in the prior 12 months, the total percentage exceeds $100 \%$; ${ }^{b}$ postbronchodilator value; ' additional COPD medications at screening in 207608/207609 included LABA and ICS monotherapies, ICS + LABA + LAMA + PDE4 inhibitor and ICS + LABA + LAMA + xanthine combination therapies and "other"; in KPNW, additional COPD medications included LABA and ICS monotherapies.

Abbreviations: BD, bronchodilator; BMI, body mass index; COPD, chronic obstructive pulmonary disease; FEV $\mathrm{V}_{1}$, forced expiratory volume in I second; ICS, inhaled corticosteroid; ITT, intent-to-treat; KPNW, Kaiser Permanente Northwest; LABA, long-acting $\beta_{2}$-agonist; LAMA, long-acting muscarinic antagonist; PDE4, phosphodiesterase 4; PIF, peak inspiratory flow; SD, standard deviation. 


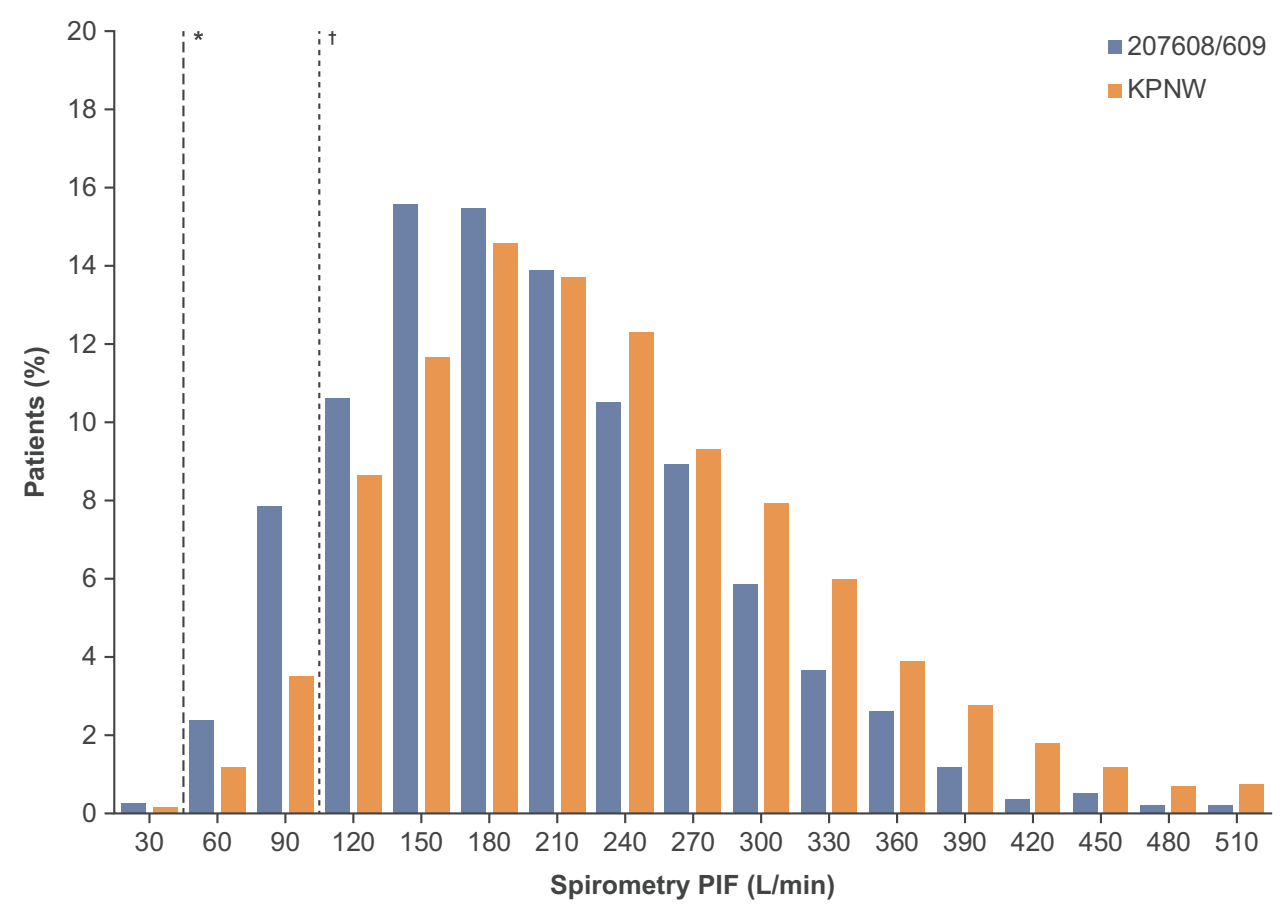

Figure I Distribution and range of spirometric PIF values at screening in studies 207608/207609 and in KPNW. *Spirometric PIF 50 L/min, estimated to be equivalent to an ELLIPTA PIF of $\geq 30 \mathrm{~L} / \mathrm{min}$; ${ }^{\dagger}$ Spirometric PIF $102 \mathrm{~L} / \mathrm{min}$, which was the recorded spirometric value in the patient with the lowest recorded ELLIPTA PIF (43.5 L/min) in the RESII38I7/RESII7I78 studies (two-strip configuration). Estimation of ELLIPTA PIF is based on the equation derived from the RESII38I7/RESII7I78 studies, where estimations of below $43.5 \mathrm{~L} / \mathrm{min}$ are based on extrapolation from spirometric PIF values below the observed minimum of $83.4 \mathrm{~L} / \mathrm{min}$. Extrapolating to $50 \mathrm{~L} / \mathrm{min}$ spirometric PIF, there is $95 \%$ confidence that $90 \%$ of the population has at least $30 \mathrm{~L} / \mathrm{min}$ ELLIPTA PIF (lower tolerance bound).

Abbreviations: KPNW, Kaiser Permanente Northwest; PIF, peak inspiratory flow.

studies, the baseline demographics and characteristics were similar in the FF/UMEC/VI and BUD/FOR+TIO treatment arms (Supplementary Table 1).

\section{Spirometric PIF Distributions in 207608/ 207609 Clinical Studies and KPNW}

There was considerable overlap between the spirometric PIFR distributions in the 207608/207609 clinical studies and the KPNW population (Figure 1).

In total, $99.7 \%(n=1945)$ of patients in the $207608 / 207609$ pooled screening population and $99.8 \%(n=3277)$ of patients in the KPNW population had a spirometric PIF $\geq 50 \mathrm{~L} / \mathrm{min}$, estimated to correspond to an ELLIPTA PIF of approximately $\geq 30 \mathrm{~L} / \mathrm{min}$ (lower tolerance bound, by use of the equation).

No correlation between spirometric PIF and the percentage predicted $\mathrm{FEV}_{1}$ at screening was evident in the 207608/207609 pooled population (Figure 2).

\section{Relationship Between Spirometric PIF and Clinical Outcomes in the Pooled 207608/207609 Population}

In the pooled 207608/207609 population, there was no statistically significant interaction between spirometric
PIF and treatment for any of the four lung function endpoints at Week 12 (0-24-hour weighted mean $\mathrm{FEV}_{1}$, trough $\mathrm{FEV}_{1}$, 12-hour $\mathrm{FEV}_{1}$ and the ratio of Week 12 to baseline trough $\mathrm{FEV}_{1}$; $\mathrm{p}$ values for interactions $>0.05$ ) (Table 2), indicating the treatment effect is not dependent on PIF. Scatter plots also showed no association between spirometric PIF and the change from baseline at Week 12 in weighted mean $\mathrm{FEV}_{1}(0-24$ hours) $(\mathrm{r}=-0.037$; Figure $3 \mathrm{~A})$ or trough $\mathrm{FEV}_{1}(\mathrm{r}=-0.028$; Figure $3 \mathrm{~B})$.

\section{Discussion}

In this analysis of clinical trial and real-world populations of patients with a wide range of COPD severities, a large distribution of spirometric PIF values were observed, with similarities and considerable overlap in the spirometric PIF distributions for the two populations. In addition, no clear association between spirometric PIF and post-treatment lung function outcomes was observed in the clinical trial population demonstrating flow-independent dose delivery. Despite patients enrolled in 207608/207609 having more severe COPD than those in the KPNW database, the overlap in spirometric PIF distributions between the two populations suggests that the patients enrolled in 207608/207609 


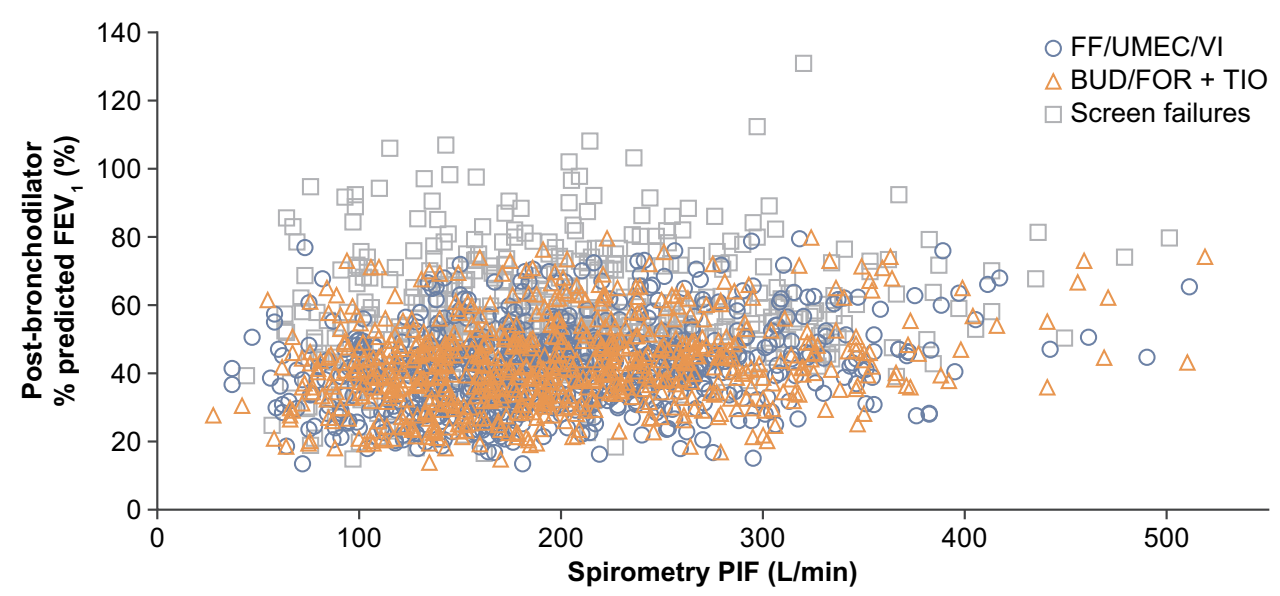

Figure 2 Relationship between spirometric PIF and post-bronchodilator percent predicted FEV at screening in pooled 207608/207609 population. Abbreviations: BUD, budesonide; FEV ${ }_{1}$, forced expiratory volume in I second; FF, fluticasone furoate; FOR, formoterol; PIF, peak inspiratory flow; TIO, tiotropium; UMEC, umeclidinium; VI, vilanterol.

studies would be able to achieve inhaler-specific PIFs similar to those in the real-world COPD population. This similarity should reassure clinicians as to the clinical validity of the results seen between spirometric PIF and post-treatment lung function outcomes in the $207608 / 207609$ population.

The distributions of spirometric PIF values at screening in the clinical trials and in the real-world population show that over $99 \%$ of patients had a spirometric PIF $\geq 50 \mathrm{~L} / \mathrm{min}$. Based on the derived equation used, nearly all of these patients are estimated to achieve an ELLIPTA PIFR of $\geq 30 \mathrm{~L} / \mathrm{min}$ (lower tolerance bound). In vitro, under standardized test conditions, a flow rate of $30 \mathrm{~L} / \mathrm{min}$ through the ELLIPTA DPI achieved mean delivered doses of FF, UMEC and VI that were $95.6 \%, 92.5 \%$ and $91.5 \%$ of their target delivery doses of 92,55 and $22 \mu \mathrm{g}$, respectively. ${ }^{22}$ In the context of these in vitro results, the current data suggest that almost all patients in the 207608/207609 and KPNW populations had sufficient inspiratory effort to achieve PIF values associated with efficient dose delivery through the ELLIPTA DPI, close to target delivery doses.
In clinical inhalation profiling studies (RES113817/ RES117178), the lowest individual value for ELLIPTA PIF for the two-strip configuration was observed in a patient with very severe COPD and was $43.5 \mathrm{~L} / \mathrm{min}^{14}$ The absence of patients with a PIF $<43.5 \mathrm{~L} / \mathrm{min}$ in the presence of moderate resistance in the RES113817/ RES117178 studies, is, in the authors' opinion, likely due to the rarity of these patients in the general population. Data from an in vitro study using the Electronic Lung breathing simulator, demonstrated that $92.7-95.5 \%(\mathrm{FF})$, 86.8-89.2\% (UMEC), and $82.7-86.8 \%$ (VI) of the nominal blister content of FF/UMEC/VI $(100 / 62.5 / 25 \mu \mathrm{g})$ was delivered when analyzed across the PIFR range 43.5$129.9 \mathrm{~L} / \mathrm{min}$, representative or inclusive of patients with COPD of all severities. ${ }^{21}$

No correlation between spirometric PIF and postbronchodilator percentage predicted $\mathrm{FEV}_{1}$ in the 207608/207609 studies was evident. This suggests that even patients with very severe airflow limitation may have PIF values associated with efficient dose delivery,

Table 2 Interactions Between Spirometric PIF at Screening and Treatment for Lung Function Endpoints in 207608/207609 Studies

\begin{tabular}{|l|l|}
\hline Week I 2 Lung Function Endpoint & p-value for Interaction of Treatment with PIF at Screening \\
\hline Weighted mean FEV , (0-24 hours) & 0.415 \\
\hline Trough FEV & 0.091 \\
\hline I2-hour FEV & 0.162 \\
\hline Trough FEV, Week I2 to baseline ratio & 0.275 \\
\hline
\end{tabular}

Notes: Analysis performed using a repeated measures model with covariates of study, baseline value, visit, geographical region, treatment, visit by treatment and visit by baseline interactions with additional terms for PIF, PIF by treatment and PIF by treatment by visit interactions.

Abbreviations: $\mathrm{FEV}_{1}$, forced expiratory volume in I second; PIF, peak inspiratory flow. 

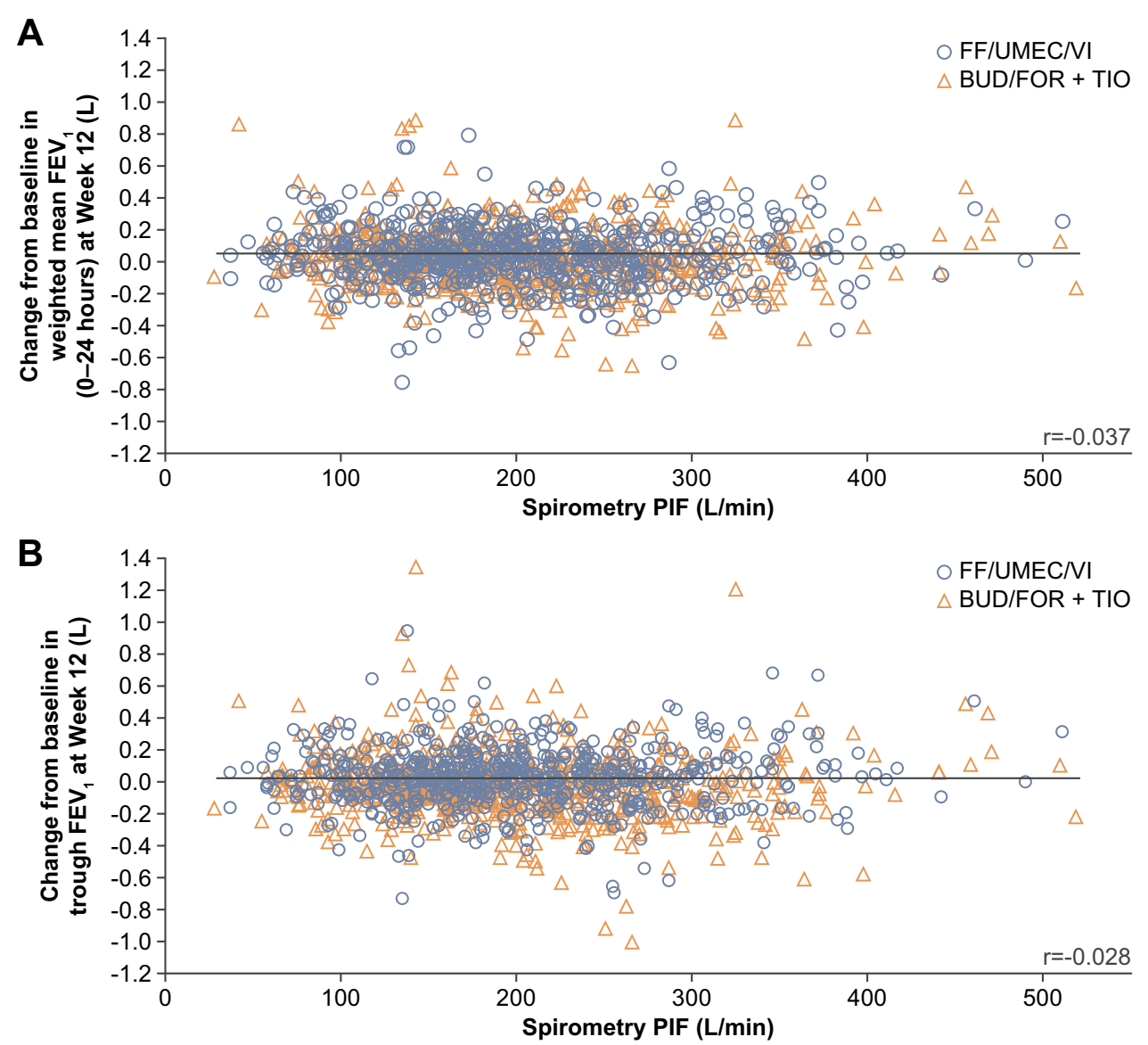

Figure 3 Relationship between spirometric PIF at screening and lung function outcomes in pooled 207608/207609 population. (A) Change from baseline in weighted mean $\mathrm{FEV}_{1}$ at Week 12 and (B) trough $\mathrm{FEV}_{1}$ at week 12.

Abbreviations: BUD, budesonide; $\mathrm{FEV}_{1}$, forced expiratory volume in I second; FF, fluticasone furoate; FOR, formoterol; PIF, peak inspiratory flow; TIO, tiotropium; UMEC, umeclidinium; VI, vilanterol.

and that baseline $\mathrm{FEV}_{1}$ is not an appropriate measure for excluding patients from using a DPI. The physiological phenomenon behind this discrepancy between flow rates in inhalation versus exhalation is commonly referred to as dynamic compression. There was no apparent difference in the range of spirometric PIF values between patients in 207608/207609 randomized to receive treatment (ITT population) and those who failed screening, indicating that patients with low PIF were not selectively excluded from the ITT population.

The GOLD treatment strategy document emphasizes the importance of education and training in inhaler device technique, as well as noting that a patient's ability must also influence the choice of inhaler. ${ }^{28}$ The In-Check DIAL device is an inhalation training meter system that simulates the internal resistance of common inhalers to help assess and educate patients on achieving the proper inhalation technique for any inhaler. ${ }^{29,30}$ When deciding whether to treat patients with DPI inhalers, clinicians may use the In-Check DIAL to measure a patient's PIF against the simulated resistance of the DPI to determine if the patient is able to achieve adequate PIF for efficient dose delivery, with an opportunity to re-educate the patient on the correct inhalation technique needed for that inhalation device. ${ }^{29,31}$ Despite training, DPIs may not be suitable for every patient due to various patient-specific physiological parameters, and in such instances those patients will need to use an alternative delivery system for their COPD medications. Previously, concerns have been raised regarding the efficacy of treatments delivered through DPIs in patients with COPD who achieve a PIF $<60 \mathrm{~L} / \mathrm{min}$, with or without device-specific resistance based on trials and retrospective analyses with small sample sizes. ${ }^{6,8,9,15,32}$ For example, in one study of 123 patients hospitalized and in an acute exacerbation of COPD care plan, $52 \%$ had PIF of $<60 \mathrm{~L} / \mathrm{min}$ in the absence of resistance and these patients had high rates of 90day readmission for COPD, days to all-cause mortality, and days to COPD readmissions ${ }^{32}$ However, a recent study comparing the PIF generated from patients with moderate-to-very- 
severe COPD through three types of DPI, found that patients produced mean PIF values $\geq 60 \mathrm{~L} / \mathrm{min}$ for two of the three DPIs tested, with values of $108 \pm 23$ and $78 \pm 15 \mathrm{~L} / \mathrm{min}$ recorded for the Breezhaler and the ELLIPTA, respectively. This provides further support that patients using ELLIPTA are able to achieve a PIF that should not negatively impact the effectiveness of inhalation therapy. ${ }^{33}$ The results presented in this post hoc analysis of two large RCTs including 1945 patients, show that nearly all patients achieved sufficient PIF and consequently there was no association between spirometric PIF and lung function outcomes, as measured by change from baseline in weighted mean $\mathrm{FEV}_{1}$ (0-24 hours) and trough $\mathrm{FEV}_{1}$ in the 207608/207609 studies, for either triple-therapy treatment group. A wide distribution of outcome values by spirometric PIF was also seen for both FF/UMEC/VI delivered via the moderate-resistance ELLIPTA DPI and BUD/FOR + TIO delivered by an MDI (with very low resistance) and the moderate-high-resistance Turbuhaler DPI, respectively. Furthermore, there was no evidence of a treatment interaction between lung function outcomes at Week 12 and spirometric PIF. These findings suggest that treatment efficacy with inhaled corticosteroid/long-acting muscarinic antagonist/long-acting $\beta_{2}$-agonist triple therapy does not correlate with a patient's inspiratory effort and that patients' are able to receive efficient dose delivery regardless of the type of inhaler used. Furthermore, these data support the in vitro evidence of dose delivery through the ELLIPTA DPI being independent of PIF across the wide range investigated. ${ }^{7,22,27}$ The lack of association between spirometric PIF and treatment, together with the analysis of the spirometric PIF distribution graphs, indicates that nearly all patients enrolled in the 207608/207609 studies were able to achieve inspiratory flow rates that result in efficient dose delivery from a DPI. In addition, the consistency between the spirometric PIF distributions in the pooled 207608/207609 population and the real-world KPNW population further suggests that the majority of patients with COPD in clinical practice are able to achieve the inspiratory effort required for dose emission and aerosolization from a DPI.

Published clinical studies assessing the relationship between either spirometric or inhaler-specific PIF and lung function are limited. ${ }^{18,32,34}$ In a study in patients with COPD who achieved a PIF $<60 \mathrm{~L} / \mathrm{min}$ against the resistance of the Diskus DPI, no significant difference in the improvement in trough $\mathrm{FEV}_{1}$ was observed between nebulized delivery of the bronchodilator revefenacin, and DPIadministration of the bronchodilator $\mathrm{TIO}^{34}$ In a post hoc analysis based on device-specific PIF quintiles, there was suggestion of a greater benefit of nebulization versus DPI in one of the quintiles (device-specific PIF $>33-<45 \mathrm{~L} / \mathrm{min}$ ) in the ITT population; however, substantial variability in all quintiles was noted and patient numbers were low. ${ }^{34}$ In an observational study of patients hospitalized for a COPD exacerbation, patients with $\mathrm{PIF}<60$ or $\geq 60 \mathrm{~L} / \mathrm{min}$ (assessed with the InCheck DIAL set to simulate the resistance of the Diskus DPI) had similar all-cause rehospitalization rates during the 180-day follow-up period, although the authors noted the small patient samples and the need for larger studies to evaluate the impact of PIF on rehospitalizations. ${ }^{18}$ Conversely, in a retrospective analysis of hospitalized patients enrolled in an acute exacerbation COPD care plan, suboptimal PIF, defined as $<60 \mathrm{~L} / \mathrm{min}$ against no resistance, was associated with higher rates of 90-day rehospitalization and days to all-cause or COPD rehospitalization. ${ }^{32}$ However, PIF was measured against no resistance in this study because not all patients were discharged with DPIs; the authors acknowledged this to be a study limitation and to preclude easy comparisons with other studies. In addition, the complex process leading to COPD rehospitalizations was highlighted, together with the factors unaccounted for, such as socioeconomic factors, healthcare and medication compliance, healthcare access and other significant comorbidities. ${ }^{32}$

Limitations of the current analysis include the relatively short duration of the 207608/207609 clinical studies (12 weeks) and the general difficulties in accurately recording spirometric inspiratory flow; however, the completion of at least three acceptable spirometric PIF measurements to obtain the value reported, was in accordance with results from a previous investigation into repeatability limits of PIF testing. ${ }^{35}$ The relatively small proportion of patients with $\mathrm{FEV}_{1} \%$ predicted $<30 \%$ precluded further analysis of these patients, who may represent those patients that would be at greatest risk for reduced PIF. The KPNW inclusion criterion requiring patients to have consistent use of the health system and healthcare insurance may have reduced applicability of the results to patients who do not routinely access healthcare or have no or low levels of healthcare insurance. A further limitation of this study is the lack of factors, other than inspiratory effort, included in the analysis that may affect PIF and therefore may limit the impact of this analysis. It is known that physical and mental capabilities, such as arthritis, dementia and cognitive function, as well as respiratory muscle weakness may all influence PIF, and some of these factors may make treatment with a nebulizer rather than a DPI inhaler more suitable for some patients. ${ }^{31,36}$ 
Factors that were not accounted for in this analysis, such as gender, height and age have also been suggested as risk factors for low PIF. ${ }^{8,18}$ Furthermore, elements of inhaler technique that are known to relate to problems with inspiratory flow, such as adequate breath hold, were not explored in this analysis. ${ }^{28,37}$ Finally, inspiratory maneuvers performed based on coached spirometry may differ from efforts used by patients during routine drug inhalation through a DPI, for example usually only one attempt is made at inhalation from an inhaler rather than multiple attempts as used in this study. It should also be noted that, although training in inhaler device technique is emphasized in the GOLD treatment strategy document, not all patients in a "real world" setting may have access to such coaching. ${ }^{28,38}$ The key strengths of this analysis are the large sizes of the populations from pooled clinical trials and a real-world database, the similarity in spirometric PIF distributions between these two populations and the use of available data from routine spirometry rather than measured device-dependent inhalation profiles. This analysis has demonstrated a novel observation through the interaction testing of PIF and four different well-established lung function parameters demonstrating no relationship and this finding is relevant to helping physicians further clarify the absence of a role of PIF and lung function improvements.

\section{Conclusion}

In conclusion, nearly all patients enrolled in the 207608/207609 studies and observed in a real-world database demonstrated spirometric PIF values that were estimated to be equivalent to ELLIPTA PIF values previously shown to result in efficient and consistent in vitro drug delivery. The lack of correlation between spirometric PIF and treatment efficacy supports the largely flow-independent dose delivery of FF/UMEC/VI from the ELLIPTA DPI across a wide range of PIFs representative of patients with COPD of all severities. Future research should be directed at longer-term studies assessing patient PIF and clinical outcomes.

\section{Abbreviations}

$\mathrm{BD}$, bronchodilator; BMI, body mass index; BUD, budesonide; CAT, COPD Assessment Test; COPD, chronic obstructive pulmonary disease; DPI, dry powder inhaler; $\mathrm{FEV}_{1}$, forced expiratory volume in 1 second; FF, fluticasone furoate; FOR, formoterol; ICS, inhaled corticosteroid; ITT, intent-to-treat; GOLD, Global Initiative for
Obstructive Lung Disease; KPNW, Kaiser Permanente Northwest; LABA, long-acting $\beta_{2}$-agonist; LAMA, longacting muscarinic antagonist; MDI, metered dose inhaler; PDE4, phosphodiesterase 4; PIF, peak inspiratory flow; RCT, randomized controlled trial; SD, standard deviation; TIO, tiotropium; UMEC, umeclidinium; VI, vilanterol.

\section{Data Sharing Statement}

Anonymized individual participant data and study documents can be requested for further research from www. clinicalstudydatarequest.com.

\section{Ethics Approval and Informed Consent}

The 207608/207609 studies were approved by the relevant ethics committee or institutional review board, in accordance with the International Council for Harmonisation of Technical Requirements for Registration of Pharmaceuticals for Human Use Good Clinical Practice and applicable country-specific requirements. ${ }^{24}$ Ethical approval of this study was provided by Kaiser Permanente - Northwest Region Institutional Review Board (approval number: 1394778) and a waiver of informed consent was granted. All accessed data complied with national data protection and privacy regulations.

\section{Acknowledgments}

Editorial support (in the form of writing assistance, assembling figures, collating author comments, grammatical editing and referencing) was provided by Philip Chapman, at Fishawack Indicia Ltd, UK, part of Fishawack Health, and was funded by GSK.

\section{Author Contributions}

All authors made a significant contribution to the work reported, whether that is in the conception, study design, execution, acquisition of data, analysis and interpretation, or in all these areas; took part in drafting, revising or critically reviewing the article; gave final approval of the version to be published; have agreed on the journal to which the article has been submitted; and agree to be accountable for all aspects of the work.

\section{Funding}

These studies were funded by GSK (study number 207608; NCT03478683; study number 207609; NCT03478696). The funders of the study had a role in 
the study design, data analysis, data interpretation, and writing of the report. ELLIPTA and Diskus are owned by or licensed to the GSK Group of Companies. HandiHaler is a trademark of Boehringer Ingelheim International $\mathrm{GmbH}$.

\section{Disclosure}

MA has received speaker fees from AstraZeneca, Boehringer Ingelheim, GSK, MEDA, Orion Pharma and Teva. MBD has received personal fees from AstraZeneca, Boehringer Ingelheim, GSK, Midmark, Teva, Mylan Theravance and Phillips, and has received research grant funding from Boehringer Ingelheim. RAM has received a collaborative research grant from GSK and research grants from PCORI and the COPD Foundation and served on a GSK Advisory Board in 2020. MT does not own any shares in pharmaceutical companies. He has received speaker's honoraria for speaking at sponsored meetings or satellite symposia at conferences from GSK and Novartis. He has received honoraria for attending advisory panels with Boehringer Ingelheim, GSK and Novartis. GTF has received grants, personal fees, and non-financial support from AstraZeneca, Boehringer Ingelheim, GSK, Novartis, Pearl Therapeutics, Sunovion, Theravance and Verona unrelated to this work; grants and personal fees from Sanofi; grants from Altavant and Knopp; personal fees from Circassia, Mylan, Galderma, Innoviva, Orpheris, and Teva unrelated to this work. $\mathrm{KC}$ and $\mathrm{NM}$ were employees of GSK at the time of the analyses and own stocks and shares in GSK. MH, RJ, and C-QZ are employees of GSK and hold stocks and shares in GSK. The authors report no other conflicts of interest in this work.

\section{References}

1. Anderson P. Patient preference for and satisfaction with inhaler devices. Eur Respir Rev. 2005;14(96):109-116. doi:10.1183/ 09059180.05.00009606

2. van der Palen J, Thomas M, Chrystyn H, et al. A randomised open-label cross-over study of inhaler errors, preference and time to achieve correct inhaler use in patients with COPD or asthma: comparison of ELLIPTA with other inhaler devices. NPJ Prim Care Respir Med. 2016;26(1):16079. doi:10.1038/npjpcrm.2016.79

3. Janson C, Henderson R, Lofdahl M, Hedberg M, Sharma R, Wilkinson AJK. Carbon footprint impact of the choice of inhalers for asthma and COPD. Thorax. 2020;75(1):82-84. doi:10.1136/thoraxjnl-2019-213744

4. Jain R, Baylis L, Sutton L, Patel P, Collison K, Sharma R. A meta-analysis of the ease of use and correct use of placebo ELLIPTA dry powder inhaler in subjects with chronic obstructive pulmonary disease. CHEST. 2019;P4220.

5. Dolovich M. New propellent-free technologies under investigation. J Aerosol Med. 2010;12:S-9.
6. Mahler DA. Peak inspiratory flow rate as a criterion for dry powder inhaler use in chronic obstructive pulmonary disease. Ann Am Thorac Soc. 2017;14(7):1103-1107. doi:10.1513/AnnalsATS.201702-156PS

7. Hamilton M, Leggett R, Pang C, Charles S, Gillett B, Prime D. In vitro dosing performance of the ELLIPTA(R) Dry powder inhaler using asthma and COPD patient inhalation profiles replicated with the electronic lung (eLung). J Aerosol Med Pulm Drug Deliv. 2015;28(6):498-506. doi:10.1089/jamp.2015.1225

8. Ghosh S, Pleasants RA, Ohar JA, Donohue JF, Drummond MB. Prevalence and factors associated with suboptimal peak inspiratory flow rates in COPD. Int $J$ Chron Obstruct Pulmon Dis. 2019;14:585-595. doi:10.2147/COPD.S195438

9. Ghosh S, Ohar JA, Drummond MB. Peak inspiratory flow rate in chronic obstructive pulmonary disease: implications for dry powder inhalers. J Aerosol Med Pulm Drug Deliv. 2017;30(6):381-387. doi:10.1089/jamp.2017.1416

10. Malmberg LP, Rytila P, Happonen P, Haahtela T. Inspiratory flows through dry powder inhaler in chronic obstructive pulmonary disease: age and gender rather than severity matters. Int J Chron Obstruct Pulmon Dis. 2010;5:257-262. doi:10.2147/COPD.S11474

11. Chen HI, Kuo CS. Relationship between respiratory muscle function and age, sex, and other factors. J Appl Physiol. 1989;66(2):943-948. doi:10.1152/jappl.1989.66.2.943

12. Dewar MH, Jamieson A, McLean A, Crompton GK. Peak inspiratory flow through Turbuhaler in chronic obstructive airways disease. Respir Med. 1999;93(5):342-344. doi:10.1016/S0954-6111(99) 90316-5

13. Seheult JN, Costello S, Tee KC, et al. Investigating the relationship between peak inspiratory flow rate and volume of inhalation from a Diskus Inhaler and baseline spirometric parameters: a cross-sectional study. Springerplus. 2014;3(1):496. doi:10.1186/ 2193-1801-3-496

14. Prime D, de Backer W, Hamilton M, et al. Effect of disease severity in asthma and chronic obstructive pulmonary disease on inhaler-specific inhalation profiles through the ELLIPTA(R) dry powder inhaler. J Aerosol Med Pulm Drug Deliv. 2015;28(6):486-497. doi:10.1089/jamp.2015.1224

15. Mahler DA. Peak inspiratory flow rate: an emerging biomarker in chronic obstructive pulmonary disease. Am J Respir Crit Care Med. 2019;199(12):1577-1579. doi:10.1164/rccm.201901-0005LE

16. Palander A, Mattila T, Karhu M, Muttonen E. In vitro comparison of three salbutamol-containing multidose dry powder inhalers. Clin Drug Investig. 2012;20:25-33. doi:10.2165/00044011-20002001000004

17. Borgstrom L, Bondesson E, Moren F, Trofast E, Newman SP. Lung deposition of budesonide inhaled via Turbuhaler: a comparison with terbutaline sulphate in normal subjects. Eur Respir J. 1994;7 (1):69-73. doi:10.1183/09031936.94.07010069

18. Sharma G, Mahler DA, Mayorga VM, Deering KL, Harshaw O, Ganapathy V. Prevalence of low peak inspiratory flow rate at discharge in patients hospitalized for COPD exacerbation. Chronic Obstr Pulm Dis. 2017;4(3):217-224. doi:10.15326/ jcopdf.4.3.2017.0183

19. Chen SY, Huang CK, Peng HC, Yu CJ, Chien JY. Inappropriate peak inspiratory flow rate with dry powder inhaler in chronic obstructive pulmonary disease. Sci Rep. 2020;10(1):7271. doi:10.1038/s41598020-64235-6

20. Janssens W, VandenBrande P, Hardeman E, et al. Inspiratory flow rates at different levels of resistance in elderly COPD patients. Eur Respir J. 2008;31(1):78-83. doi:10.1183/09031936.00024807

21. Prime D, Hamilton M, Taylor E. In-vitro product performance of fluticasone furoate (FF)/umeclidinium (UMEC)/vilanterol (VI) delivered from a dry powder inhaler (DPI) using the Electronic Lung (EL) to replicate patient inhalation profiles. European Respiratory Journal. 2019;54:PA4230. Presented at the ERS Congress 2019; SeptemberOctober; 2019:4228-4232; Madrid, Spain. 
22. Prime D, Hamilton M, Patmore D. Consistency of dose delivery of fluticasone furoate (FF)/umeclidinium (UMEC)/vilanterol (VI) across patient relevant inhalation flow rates from a dry-powder inhaler (DPI). CHEST. 2019;156:A1786. doi:10.1016/j.chest.2019.08.1550

23. GlaxoSmithKline. Trelegy ELLIPTA US prescribing information; 2020. Available from: https:/www.gsksource.com/pharma/content/ dam/GlaxoSmithKline/US/en/Prescribing_Information/Trelegy/pdf/ TRELEGY-ELLIPTA-PI-PIL-IFU.PDF. Accessed September, 2020.

24. Ferguson GT, Brown N, Compton C, et al. Once-daily single-inhaler versus twice-daily multiple-inhaler triple therapy in patients with COPD: lung function and health status results from two randomized controlled trials. Respir Res. 2020;21(1):131. doi:10.1186/s12931020-01360-w

25. Heddini A, Sundh J, Ekstrom M, Janson C. Effectiveness trials: critical data to help understand how respiratory medicines really work? Eur Clin Respir J. 2019;6(1):1565804. doi:10.1080/ 20018525.2019.1565804

26. Graham BL, Steenbruggen I, Miller MR, et al. Standardization of spirometry 2019 update. An Official American Thoracic Society and European Respiratory Society Technical Statement. Am J Respir Crit Care Med. 2019;200(8):e70-e88. doi:10.1164/rccm.201908-1590ST

27. Grant AC, Walker R, Hamilton M, Garrill K. The ELLIPTA(R) dry powder inhaler: design, functionality, in vitro dosing performance and critical task compliance by patients and caregivers. J Aerosol Med Pulm Drug Deliv. 2015;28(6):474-485. doi:10.1089/ jamp.2015.1223

28. Global Initiative for Chronic Obstructive Lung Disease. Global strategy for the diagnosis, management, and prevention of chronic obstructive pulmonary disease 2020 report; 2020.

29. Clement Clarke International Ltd. Disposable inspiratory one-way mouthpiece with in-check DIAL G16, instructions for use; September 2019. Available from: https:/www.haag-streit.com/clem ent-clarke/products/inhaler-technique/in-check-dial-g16/?no_cache= 1. Accessed February, 2021.
30. Sanders MJ. Guiding inspiratory flow: development of the in-check DIAL G16, a tool for improving inhaler technique. Pulm Med. 2017;2017:1495867. doi:10.1155/2017/1495867

31. Mahler DA. The role of inspiratory flow in selection and use of inhaled therapy for patients with chronic obstructive pulmonary disease. Respir Med. 2020;161:105857. doi:10.1016/j. rmed.2019.105857

32. Loh CH, Peters SP, Lovings TM, Ohar JA. Suboptimal inspiratory flow rates are associated with chronic obstructive pulmonary disease and all-cause readmissions. Ann Am Thorac Soc. 2017;14 (8):1305-1311. doi:10.1513/AnnalsATS.201611-903OC

33. Altman P, Wehbe L, Dederichs J, et al. Comparison of peak inspiratory flow rate via the Breezhaler ${ }^{\circledR}$, Ellipta ${ }^{\circledR}$ and HandiHaler ${ }^{\circledR}$ dry powder inhalers in patients with moderate to very severe COPD: a randomized cross-over trial. BMC Pulm Med. 2018;18(1):100. doi:10.1186/s12890-018-0662-0

34. Mahler DA, Ohar JA, Barnes CN, Moran EJ, Pendyala S, Crater GD. Nebulized versus dry powder long-acting muscarinic antagonist bronchodilators in patients with COPD and suboptimal peak inspiratory flow rate. Chronic Obstr Pulm Dis. 2019;6(4).

35. Barnes CN, Mahler DA, Ohar JA, Lombardi DA, Crater GD. Peak inspiratory flows: defining repeatability limits and a predictive equation for different inhalers. Chest. 2020;158(4):1413-1419. doi:10.1016/j.chest.2020.03.072

36. Pleasants RA, Hess DR. Aerosol delivery devices for obstructive lung diseases. Respir Care. 2018;63(6):708-733. doi:10.4187/ respcare.06290

37. Sulaiman I, Cushen B, Greene G, et al. Objective assessment of adherence to inhalers by patients with chronic obstructive pulmonary disease. Am J Respir Crit Care Med. 2017;195(10):1333-1343. doi:10.1164/rccm.201604-0733OC

38. Willard-Grace R, Chirinos C, Wolf J, et al. Lay health coaching to increase appropriate inhaler use in COPD: a Randomized Controlled Trial. Ann Fam Med. 2020;18(1):5-14. doi:10.1370/afm.2461

\section{Publish your work in this journal}

The International Journal of COPD is an international, peer-reviewed journal of therapeutics and pharmacology focusing on concise rapid reporting of clinical studies and reviews in COPD. Special focus is given to the pathophysiological processes underlying the disease, intervention programs, patient focused education, and self management protocols. This journal is indexed on PubMed Central, MedLine and CAS. The manuscript management system is completely online and includes a very quick and fair peer-review system, which is all easy to use. Visit http://www.dovepress.com/testimonials.php to read real quotes from published authors. 